\title{
PANDEMIA: A VEICULAÇÃO DE NOTÍCIAS SOBRE A COVID-19 NOS SITES DE EMISSORAS DE RÁDIO DA REGIÃO CELEIRO, RS
}

\author{
Lidia Paula Trentin ${ }^{1}$
}

Resumo:

0 estudo aqui apresentado tem o intuito de verificar de que maneira as emissoras de rádio Difusora 1350 AM, Província 100.7 FM e Querência 89.7 FM veicularam conteúdo jornalístico relativo à doença Covid-19 em seus sites entre janeiro e março de 2020. Para fundamentar a pesquisa foram utilizados autores que discutem radiojornalismo e as mudanças que ocorreram com a convergência tecnológica. A técnica de pesquisa utilizada foi análise de conteúdo, a partir da qual observou-se que a veiculação de conteúdo nos sites se manteve estável nos três meses, o que mudou foi a quantidade de notícias sobre o novo coronavírus, uma vez que houve um crescimento significativo na veiculação de conteúdo sobre a Covid-19 no mês de março em relação a janeiro e fevereiro.

Palavras-chave: Pandemia; Covid-19; Radiojornalismo; Rádio e Convergência Tecnológica; Rádio na Internet.

\begin{abstract}
:
The study presented here aims to verify how the radio stations Difusora 1350 AM, Província 100.7 FM and Querência 89.7 FM broadcast journalistic content related to Covid-19 on their websites disease between January and March 2020. To support the research, authors who discuss radio journalism and the changes that occurred with technological convergence were used. The research technique used was content analysis, from which it was observed that the placement of content on the sites remained stable over the three months, what changed was the amount of news about the new coronavirus, since there was an significant growth in the delivery of content about Covid-19 in March compared to January and February.
\end{abstract}

Keywords: Pandemic; Covid-19; Radiojournalism; Radio and Technological Convergence; Internet radio.

\section{Introdução}

O surto de Covid-19, enfermidade causada pelo novo coronavírus (Sars-CoV-2 (síndrome respiratória aguda grave - coronavírus 2)), foi relatado pela primeira vez, de acordo com a Organização Mundial da Saúde (OMS) (2020a), no dia 31 de dezembro de 2019, em Wuhan, na China. O surto da doença, que causa infecções respiratórias, não pareceu, de início, tão grave quanto se tornaria, apesar de não haver muitas informações sobre o novo coronavírus. Em janeiro de 2020 a BBC News Brasil publicou uma notícia em que o governo federal e epidemiologistas ouvidos pela agência relataram que era baixo o risco de um surto no Brasil. Além disso, um infectologista entrevistado pela BBC News

\footnotetext{
1 Doutoranda e Mestre em Comunicação e Linguagens pela Universidade Tuiuti do Paraná (PPGCom/UTP). Bolsista PROSUP/CAPES. Especialista em Mídias na Educação (UFSM). Jornalista (UFSM). E-mail: lidiapaulatrentin@gmail.com
} 
Brasil (2020), explicou que, em razão da globalização, as medidas de contenção de epidemias são adotadas mais rapidamente que no passado. 0 que não foi suficiente, sobretudo pela rapidez na transmissão da doença, em decorrência disso, a partir de março de 2020, a OMS declarou a pandemia do novo coronavírus².

Informações sobre a doença se tornaram acessíveis a grande parcela da população, uma vez que notícias acerca do tema foram (e ainda são) ampla e frequentemente veiculadas em emissoras de rádio, televisão, materiais impressos e na internet. 0 rádio é um meio de comunicação muito eficiente na divulgação de informações, visto que, segundo pesquisa realizada em 2018 pela Kantar IBOPE Media em 13 regiões metropolitanas (do Distrito Federal, Belo Horizonte, Curitiba, Campinas, Florianópolis, Fortaleza, Goiânia, Porto Alegre, Recife, Rio de Janeiro, Salvador, São Paulo e Vitória), o rádio é ouvido por $86 \%$ da população nessas regiões. De acordo com o estudo (2018), o rádio hertziano ainda é o dispositivo mais utilizado (85\%), seguido pelo celular (18\%), por outros dispositivos $(5 \%)$ e pelo computador (4\%). A pesquisa demonstrou ainda que, para os ouvintes, o rádio é um meio de comunicação ágil, confiável e de fácil compreensão.

0 acesso à internet também facilitou o recebimento de informações relacionadas ao novo coronavírus. Contudo, conforme o Relatório Final da Pesquisa Brasileira de Mídia 2016, enquanto as informações veiculadas no rádio possuem um grau de confiança alto, cerca de $60 \%$, na internet, em contrapartida, a confiança é baixa, seja em sites, blogs e redes sociais, pois "a maioria dos usuários de internet confia poucas vezes ou nunca confia nas notícias" publicadas nessa mídia (PBM, 2016, p. 33).

Assim, considerando a presença do rádio no cotidiano do público e o grau de confiabilidade das informações transmitidas, optou-se por estudar conteúdos veiculados por emissoras de rádio, entretanto, como o meio é fugaz, decidiu-se verificar as informações divulgadas em seus canais na internet, mais especificamente, seus sites, devido à durabilidade do conteúdo.

As emissoras selecionadas foram: Difusora 1350 AM, de Três Passos, Província 100.7 FM, de Tenente Portela e Querência 89.7 FM (migrou em 2019 do AM 1120), de Santo Augusto, localizadas na Região Celeiro, Noroeste do estado do Rio Grande do Sul. As três emissoras foram escolhidas para o estudo por serem Rádios com programações, características e públicos distintos, visto que uma delas é AM ainda em processo de

\footnotetext{
2 Informações em reportagem veiculada no G1. Disponível em: <https://g1.globo.com/bemestar/coronavirus/noticia/2020/03/11/oms-declara-pandemia-decoronavirus.ghtml>. Acesso em: 20 mai. 2020.
} 
migração (Difusora), outra migrou do AM para o FM recentemente (Querência) e, por fim, uma das emissoras é originalmente FM (Província). Além disso, as três estão localizadas em municípios diferentes.

Dessa forma, o presente estudo tem como objetivo geral verificar de que forma as emissoras de rádio Difusora 1350 AM, Província 100.7 FM e Querência 89.7 FM veicularam, em seus sites, conteúdos jornalísticos relativos à doença Covid-19, causada pelo Sars-CoV2, observando, sobretudo, a quantidade e o tipo de conteúdo noticiado, desde dia 01 de janeiro de 2020 (um dia após o primeiro caso na China) até o dia 31 de março de 2020, mês em que a OMS declarou a pandemia do novo coronavírus e que começaram a quarentena e o isolamento social no Brasil. Como objetivos específicos têm-se: a) averiguar a quantidade de material jornalístico publicado nos três meses de análise e, sobretudo, relacionado ao coronavírus; b) verificar a autoria das notícias, se são notícias próprias, de outros veículos de comunicação ou produzidas por assessorias de comunicação; c) apurar quais as fontes (oficiais, especializadas e não oficiais/leigas) utilizadas para a produção das notícias, bem como a origem das imagens que complementam e ilustram o conteúdo; e, por fim, d) constatar quais foram as palavras mais utilizadas nos títulos das notícias relacionadas ao Covid-19, uma vez que os termos escolhidos podem atrair ou afastar o público.

Sustentam a pesquisa pressupostos de autores que discutem radiojornalismo e as mudanças que ocorreram com a convergência tecnológica, que serão apresentados a seguir.

\section{Rádio em tempos de convergência tecnológica}

Estamos na era de um rádio que, além de ser via dial, também tem presença na internet. Essa nova forma de radiofonia é chamada de “ciber-rádio" por Cebrián Herreros (2008), “rádio hipermidiático" por Lopez (2009) e “rádio expandido” por Marcelo Kischinhevsky (2012). Kischinhevsky (2012, p. 137) explica que é um rádio que "transborda para mídias sociais e microblogs, que potencializam seu alcance e a circulação de seus conteúdos, muitas vezes substituindo a entrada no ar de ouvintes ao vivo por telefone e redesenhando as formas de apropriação pela audiência".

Além disso, 
novamente, característica da instantaneidade, ou seja, a simultaneidade na recepção. Na Web, mesmo nas transmissões ao vivo, os sites podem disponibilizar os arquivos de áudio para que os ouvintes possam escutá-los posteriormente, on demand. As rádios virtuais são especialmente produzidas para a Internet; mas emissoras convencionais a utilizam como suporte para suas transmissões normais. A presença do rádio na WWW, por enquanto, é tão diversificada quanto a própria Internet. Tudo pode ser encontrado, de emissoras altamente especializadas a meras caixas de música, para muitos gostos (ORTRIWANO, 2002-2003, p. 81).

São várias as mudanças que ocorreram no rádio como consequência da convergência, a fugacidade da mensagem, por exemplo, existente no rádio tradicional, pode ser evitada no rádio com transmissão online, uma vez que há a possibilidade de veicular conteúdo em forma de texto, imagens, vídeos e o próprio áudio da transmissão ao vivo pode ser postado em formato de podcast. Prata (2009, p. 43) explica que, com a internet, surgiu também uma nova forma de radiofonia, na qual o público pode, além de ouvir as mensagens veiculadas, também encontrá-las em diversos outros formatos, "além do áudio, há toda uma profusão de elementos textuais e imagéticos que ressignificam o velho invento de Marconi". Apesar de o rádio contar com todas essas alternativas para complementar o conteúdo veiculado, para que continue sendo genuinamente rádio, é necessário que haja a transmissão ao vivo de sons (tanto na internet quanto via dial).

Assim como Brecht idealizava já na década de 1920. Atualmente, a participação do público, até mesmo como produtor de conteúdo, é possível graças à internet e a convergência das mídias. Inclusive, Ferraretto (2001, p. 196) afirma que "o rádio é um veículo interativo por excelência". O autor (2001) aponta que há emissoras que estabeleceram determinados espaços específicos nas programações para a participação dos ouvintes, como programas com enquetes e sorteios, por exemplo.

O avanço tecnológico possibilitou novas formas de interação entre público e mídias. A internet, as redes sociais, bem como os novos dispositivos utilizados na comunicação, aproximaram os meios de seus receptores, facilitando essa interação. Hoje, segundo Lopez (2009) os smartphones, por exemplo, que agregam acesso a rádio FM, à internet, mensagens de texto e multimídia e Bluetooth, permitem acesso, envio e recebimento de conteúdos dos mais diversos tipos - como áudio, vídeos, imagens, texto e infográficos -, e esses conteúdos são incorporados como parte da narrativa, escuta e participação no rádio. A interatividade varia de emissora para emissora, algumas permitem a cooperação dos ouvintes na programação, outras restringem esse tipo de participação. 
O ouvinte do "rádio hipermidiático", que surgiu com a convergência tecnológica, é chamado “Ouvinte-Internauta” por Lopez (2009, 141), "tem um perfil mais dinâmico e ágil, que busca complementações, interação e personalização de conteúdo", e passa, cada vez mais, a participar ativamente dos programas, sugerindo discussões, perguntas, fontes de informação, em suma, fazendo parte da produção radiofônica. Agora há, inclusive, a possibilidade de os ouvintes tronarem-se também produtores de informação (PRATA, 2009).

Assim como os ouvintes, os profissionais do rádio também se reinventaram frente às mudanças tecnológicas que têm ocorrido, uma vez que precisam além de apreender que o público mudou a forma de ouvir rádio - se tornou mais ativo e participante na programação -, produzir conteúdo multimídia para alimentar, com conteúdo, sites, blogs e redes sociais. Ou seja, esse rádio, com presença na internet demanda do locutor muito mais do que apenas falar bem no rádio ao vivo e ter um vocabulário de fácil compreensão, é preciso ser um profissional multitarefas e multimidiático. Essas características estão se tornando, com o avanço das tecnologias, cada vez mais, critérios na seleção de novos radialistas.

\section{A Rádio Difusora AM 1350}

Criada no dia 20 de setembro de $1951^{3}$, a Rádio Difusora, de Três Passos, foi a primeira emissora de rádio da Região Celeiro do Rio Grande do Sul. No início como uma sucursal da Rádio Sulina, de Santa Rosa. Depois, da Rádio Colonial, de Três de Maio. Mais tarde foi transformada em emissora local, com o nome de Difusora. A emissora começou a operar com uma potência de 250 watts, logo após foi elevada para 1.000 watts ampliando sua área de cobertura para outros pontos do estado, para o nordeste da Argentina e para os estados de Santa Catarina e Paraná. Na década de 1990, a Difusora passou por transformações: elevando sua potência para 5 mil watts e alterando a localização da antena para proporcionar um melhor desempenho.

A rádio Difusora AM é uma das afiliadas da Rede Gaúcha Sat e faz parte de um sistema de comunicação que conta com a emissora, um jornal impresso e um site de notícias (remetendo à emissora e ao jornal). Além disso, está em processo de migração, o termo aditivo de adaptação de outorga de AM para FM foi assinado em 2014 e a Rádio está esperando uma frequência do MCTIC.

\footnotetext{
${ }^{3}$ Dados obtidos por meio de arquivo enviado por uma funcionária da emissora pelo chat do Facebook em 21 ago. 2019.
} 
A programação é variada, conta com programas musicais - abrangendo todos os gêneros -, e jornalísticos. Aos domingos, entre $12 \mathrm{~h} 45$ e 15h00, a emissora transmite programas culturais italianos e alemães. Programas religiosos são veiculados apensas aos finais de semana.

\section{Rádio Província 100.7 FM}

O início das atividades da Rádio Província FM se deu em 17 de junho de $1989^{4}$. É uma das primeiras emissoras FM do noroeste do estado do Rio Grande do Sul. Instalada em Tenente Portela, foi criada pelo jornalista Jalmo Fornari, e atinge hoje toda a região noroeste do Estado, além de municípios do oeste de Santa Catarina, sul do Paraná e Norte da Argentina.

Desde 1999 a emissora é uma das afiliadas da Rede Gaúcha Sat. Veiculando, ao longo de sua programação, as "Notícias na Hora Certa" de hora em hora, o “Correspondente Ipiranga" em quatro edições diárias e as “Jornadas Esportivas” com a cobertura de todos os eventos esportivos.

Assim como a Rádio Difusora, a emissora faz parte de um sistema de comunicação chamado Sistema Província, que conta além da Rádio, com um jornal impresso e um site de notícias (que remete à emissora e ao jornal).

Com programação diversificada, a emissora transmite programas musicais e jornalísticos, sendo esses últimos veiculados de hora em hora. Não veicula programação religiosa, com exceção das missas da Igreja Católica Matriz de Tenente Portela, todos os domingos às 9 h00 da manhã.

\section{A Rádio Querência FM 89,7 (AM 1120)}

O Ministério da Ciência, Tecnologia, Inovações e Comunicações - MCTIC concedeu, no dia 6 de janeiro de $1988^{5}$, a Licença de Concessão da Rádio Querência de Santo Augusto Ltda. para a instalação de uma emissora de Ondas Médias na frequência de $1540 \mathrm{KHZ}$ com 1.000 Watts de potência. A emissora recebeu o Prefixo ZYK 367 e sua programação foi ao

\footnotetext{
${ }^{4}$ Dados obtidos por meio de entrevista com o fundador da Emissora e com informações do site. Disponível em: <http://www.yucuma.com.br/institucional/4/Histria.html>. Acesso em: 25 mar. 2019.

${ }^{5}$ Dados obtidos no site da Emissora. Disponível em: <https://www.querenciaonline.com/historico/>. Acesso em: 18 jul. 2019.
} 
ar em 11 de setembro de 1988. Em abril de 2019 a emissora concluiu o processo de migração, passando a operar na FM 89.7 com 10 mil watts de potência.

A Rádio conta com programas jornalísticos e musicais, e, assim como as emissoras Difusora AM e Província FM, também é uma das afiliadas da Rede Gaúcha Sat. Desde 2007, o projeto Rádio Querência em Minha Escola, que tem como objetivo a interação entre alunos, professores e meio de comunicação. 0 projeto é executado mediante cronograma estabelecido com as escolas, e vai ao ar ao vivo, por duas horas, direto dos educandários.

A Emissora possui uma programação variada, com programas jornalísticos e musicais. Uma característica da Rádio são os programas religiosos, que possuem grande presença na grade da emissora, sendo veiculados diariamente.

\section{Metodologia}

Para apurar de que maneira as emissoras de rádio mencionadas veicularam em seus sites notícias sobre a pandemia optou-se pelo método de análise de conteúdo, por ser uma técnica de pesquisa híbrida, ou seja, pode ser quantitativa ou qualitativa (BAUER, 2008). 0 pesquisador pode criar categorias para a investigação, e essas categorizações são, conforme Bardin (1977, p. 117) "rubricas ou classes, as quais reúnem um grupo de elementos (unidades de registo, no caso da análise de conteúdo) sob um título genérico, agrupamento esse efetuado em razão dos caracteres comuns destes elementos".

As categorias são definidas pelo próprio pesquisador, de acordo com as necessidades do estudo. Isto posto, a análise do conteúdo das notícias referentes ao novo coronavírus nos sites das rádios Difusora 1350 AM, Província 100.7 FM e Querência 89.7 FM se deu a partir das seguintes categorias: total de notícias; total de notícias sobre a Covid19; notícias sobre a Covid-19 no mundo, no Brasil, no Rio Grande do Sul e na Região Celeiro; notícias com comentários ativados ou desativados; número de notícias próprias, de outros veículos e produzidas por assessorias de comunicação (Ascom); fontes de informação (oficiais, não oficiais, especializadas ou sem fonte); origem das imagens e vídeos (se houver) (próprios, de outros veículos ou apenas ilustrativos); links utilizados para complementar o conteúdo veiculado (para o próprio site, para sites de outros meios de comunicação ou para sites de empresas); e, por fim, quais as palavras mais utilizadas nos títulos das notícias sobre coronavírus. 
O período de análise teve início no dia 01 de janeiro de 2020 (visto que o primeiro caso da Covid-19 ocorreu em 31 de dezembro de 2019, surto que depois tomou grandes proporções a ponto de se tornar uma pandemia) até o final de março, mês em que a OMS declarou a doença como pandêmica e que tiveram início a quarentena e o isolamento social no Brasil e em diversos outros países do mundo.

\section{A veiculação de notícias sobre a Covid-19}

Quadro 1. Número total de notícias e acerca do novo coronavírus

\begin{tabular}{|l|l|l|l|l|}
\hline \multicolumn{1}{|c|}{ Emissora } & \multicolumn{1}{c|}{ Janeiro } & \multicolumn{1}{c|}{ Fevereiro } & \multicolumn{1}{c|}{ Março } & \multicolumn{1}{c|}{ TOTAL } \\
\hline Difusora 1350 AM & 130 e 3 & 123 e 5 & 91 e 31 & 344 e 39 \\
\hline Província 100.7 FM & 194 e 2 & 120 e 3 & 320 e 163 & 634 e 168 \\
\hline Querência 89.7 FM & 197 e 5 & 125 e 5 & 221 e 135 & 543 e 145 \\
\hline
\end{tabular}

Fonte: a autora (2020).

Enquanto em janeiro e fevereiro as três emissoras veicularam, em seus sites, apenas 23 notícias sobre a pandemia, de um total de 889 (uma média de pouco mais de 2,5 - 1,6\% Província, 3,1\% Querência e 3,2\% Difusora), em março esse número subiu para 329 de 632, ou seja, mais de 50\% (34\% Difusora, 51\% Província e 61\% Querência).

Levando em consideração o total de notícias publicadas em cada site durante o período de análise, a emissora que mais veiculou matérias sobre a doença durante os três meses analisados foi a rádio Querência, com 145 um total de 543 (ou seja, 26,7\%), seguida da Província, com 168 de 634 (26,5\%) e, por fim, a Difusora, com 39 de 344 (11,5\%) de conteúdo postado relacionado à Covid-19.

No que diz respeito ao número total das três emissoras, a rádio Província supera a Querência em 23 matérias sobre o novo coronavírus e 91 no total de notícias publicadas, esse é o motivo de a rádio Querência possuir uma porcentagem levemente maior que a Província em relação a conteúdo acerca da doença. 
Quadro 2. Site da Rádio Difusora 1350 AM

\begin{tabular}{|c|c|c|c|}
\hline \multicolumn{4}{|c|}{ Notícias } \\
\hline $\begin{array}{l}\text { Total de outras notícias: } \\
344\end{array}$ & $\begin{array}{l}\text { Total de notícias sobre } \\
\text { coronavírus: } 39\end{array}$ & & \\
\hline Notícias próprias: 6 & $\begin{array}{lll}\text { Notícias } & \text { de } & \text { outros } \\
\text { meios: } 18 & & \\
\end{array}$ & Notícias de Ascom: 15 & \\
\hline Covid-19 no Mundo: 7 & Covid-19 no Brasil: 11 & $\begin{array}{l}\text { Covid-19 no Rio Grande } \\
\text { do Sul: } 9\end{array}$ & Covid-19 na Região: 12 \\
\hline $\begin{array}{l}\text { Comentários ativados: } \\
36\end{array}$ & $\begin{array}{l}\text { Comentários } \\
\text { desativados: } 3\end{array}$ & Com comentários: 0 & Sem comentários: 39 \\
\hline \multicolumn{4}{|c|}{ Fontes } \\
\hline Fontes oficiais: 35 & Fontes especializadas: 2 & Não oficiais: 2 & Sem fonte: 1 \\
\hline \multicolumn{4}{|c|}{ Fotos } \\
\hline Fotos próprias: 0 & Fotos ilustrativas: 17 & $\begin{array}{l}\text { Fotos de outros meios: } \\
21\end{array}$ & Sem fotos: 1 \\
\hline \multicolumn{4}{|c|}{ Vídeos } \\
\hline Vídeos próprios: 0 & De outros meios: 1 & Sem vídeos: 38 & \\
\hline \multicolumn{4}{|c|}{ Links } \\
\hline Para o próprio site: 0 & Para outros meios: 8 & Sem link: 31 & \\
\hline
\end{tabular}

Fonte: a autora (2020).

Em janeiro a emissora não postou quaisquer conteúdos noticiosos no site durante os finais de semana, ou seja, foram 10 dias sem notícias, em fevereiro foram nove dias e, em março, oito. No que se refere a conteúdo acerca da Covid-19, foram três dias em janeiro com matérias sobre o assunto, três dias em fevereiro e 13 em março.

Durante o período analisado, a Rádio Difusora 1350 AM publicou 344 notícias em seu site, sendo que $39(11,5 \%)$ tratavam sobre o novo coronavírus. Destas, seis $(15,5 \%)$ eram notícias próprias, 18 (46\%) de outros meios e 15 (38,5\%) de assessorias de comunicação. Das $33(84,5 \%)$ que não foram produzidas pela emissora, $16(48,5 \%)$ foram de meios nacionais e $17(51,5 \%)$ de estaduais e regionais, principalmente: Ascom de Três Passos, 10 (30,5\%), Agência Brasil, oito (24\%) e G1, cinco (15\%). Ou seja, dos 33 meios utilizados para obtenção de informações, 23 (69,6\%) foram dos três citados.

Notícias sobre a Covid-19 na Região Celeiro foram as mais frequentes, com 12 (31\%), seguidas de coronavírus no Brasil, 11 (28\%), no Rio Grande do Sul, nove (23\%) e no 
mundo, sete (18\%). Os comentários estavam ativados em 36 delas, apenas três não permitiam que o público comentasse, entretanto, não houve nenhum.

As fontes de informação ${ }^{6}$ utilizadas nas notícias publicadas foram, sobretudo, oficiais, contando com 35 (90\%), seguidas de fontes especializadas (médicos), duas (5\%), não oficiais (diretores de empresas) também com duas $(5 \%)$ e uma $(2,5 \%)$ das matérias não possuía fonte. As principais fontes oficiais utilizadas nas notícias publicadas pela emissora foram: Governos: 26 (74\%), OMS: 5 (14\%) e Ministério da Saúde: 4 (11,5\%).

A Rádio Difusora 1350 AM não produziu nenhuma foto própria para as matérias, para ilustrar ou complementar o conteúdo, a emissora usou de 21 (54\%) fotos de outros meios e $17(43,5 \%)$ fotos ilustrativas. Uma das matérias não possuía imagem $(2,5 \%)$.

Apenas uma das notícias postadas contou com vídeo, que foi produzido por outro meio, que não a Rádio Difusora. Quanto aos links, 31 (79,5\%) das matérias não os possuía, $8(20,5 \%)$ tinham links para outros meios e nenhuma para o site da própria emissora.

Há imagens sem créditos do fotógrafo e as informações sobre os veículos e autores das notícias, sobretudo, logo após os títulos, no entanto há casos em que essas informações são apresentadas ao final do texto. Algumas matérias possuem mais de um link e mais de uma fonte.

Algumas das notícias postadas apresentam decretos na íntegra, tornando-se, assim, muito longas.

Quadro 3. Palavras mais utilizadas nos títulos das notícias da Rádio Difusora 1350 AM

\begin{tabular}{|l|l|}
\hline Coronavírus: 21 & Quarentena: 0 \\
\hline COVID19: 3 & Hospital/UPA/Lacen: 1 \\
\hline Pandemia: 0 & Morte: 4 \\
\hline Calamidade (pública): 2 & Auxílio (R\$ 600,00): 3 \\
\hline Suspensão: 3 & Decreto: 4 \\
\hline Ministério da Saúde: 4 & Emergência/emergencial: 2 \\
\hline
\end{tabular}

Fonte: a autora (2020).

As palavras utilizadas nos títulos das notícias podem ser determinantes no acessar ou não o seu conteúdo, uma vez que podem atrair ou desinteressar o público. Nesse sentido, o termo "Coronavírus" foi o mais recorrente nos títulos das matérias postadas no

\footnotetext{
${ }^{6}$ Nesse caso, em uma das notícias havia mais de uma fonte, por isso o número ultrapassa $100 \%$.
} 
site da Rádio Difusora 1350 AM sobre a doença, utilizada 21 vezes, enquanto "Covid-19" foi utilizada em apenas três.

Mesmo após declarada a quarentena devido à pandemia da doença, as duas expressões não foram utilizadas nenhuma vez nos títulos das matérias. A palavra "morte" foi utilizada quatro vezes, a primeira em 04 de fevereiro de 2020, em uma notícia sobre a China e, especificamente sobre mortes no Brasil, em 24 de março, sendo que a primeira morte por coronavírus no país ocorreu no dia 17 do mesmo mês.

O termo "Decreto" foi utilizado quatro vezes, sendo que a primeira foi em 21 de março, data de assinatura do documento em Três Passos (município da emissora); “Calamidade”, empregado duas vezes, a primeira em 24 de março, apesar de ter sido mencionada no decreto do dia 21, e “Auxílio / R\$ 600,00”, em três títulos, o primeiro em 27 de março, mesma data em que o repasse foi aprovado na Câmara dos Deputados. Já as palavras "Suspensão" e "Emergência/emergencial” foram utilizadas, respectivamente três e duas vezes.

Quadro 4. Site da Rádio Província 100.7 FM

\begin{tabular}{|c|c|c|c|}
\hline \multicolumn{4}{|c|}{ Notícias } \\
\hline $\begin{array}{lr}\text { Total de } & \text { outras } \\
\text { notícias: } 634 & \\
\end{array}$ & $\begin{array}{l}\text { Total de notícias sobre } \\
\text { coronavírus: } 168\end{array}$ & & \\
\hline Notícias próprias: 85 & $\begin{array}{l}\text { Notícias de } \\
\text { meios: } 54\end{array}$ & Notícias de Ascom: 29 & \\
\hline Covid-19 no Mundo: 8 & Covid-19 no Brasil: 50 & $\begin{array}{l}\text { Covid-19 no } \\
\text { Grande do Sul: } 50\end{array}$ & $\begin{array}{l}\text { Covid-19 na Região: } \\
60\end{array}$ \\
\hline $\begin{array}{l}\text { Comentários ativados: } \\
168\end{array}$ & $\begin{array}{l}\text { Comentários } \\
\text { desativados: } 0\end{array}$ & Com comentários: 15 & Sem Comentários: 153 \\
\hline \multicolumn{4}{|c|}{ Fontes } \\
\hline Fontes oficiais: 107 & $\begin{array}{l}\text { Fontes especializadas: } \\
2\end{array}$ & Não oficiais: 59 & Sem fonte: 0 \\
\hline \multicolumn{4}{|c|}{ Fotos } \\
\hline Fotos próprias: 64 & Fotos ilustrativas: 36 & $\begin{array}{l}\text { Fotos de outros meios: } \\
68\end{array}$ & Sem fotos: 0 \\
\hline \multicolumn{4}{|c|}{ Vídeos } \\
\hline Vídeos próprios: 0 & De outros meios: 0 & Sem vídeos: 168 & \\
\hline \multicolumn{4}{|c|}{ Links } \\
\hline Para o próprio site: 0 & Para outros meios: 2 & Sem link: 166 & \\
\hline
\end{tabular}


Fonte: a autora (2020).

Em janeiro a emissora deixou de postar notícias no site apenas quatro dias (aos domingos), em fevereiro um e, em março, nenhum. Quanto a conteúdo sobre o novo coronavírus, houve postagens em dois dias no mês de janeiro, também dois dias em fevereiro e 23 em março.

Foram publicadas no site da Rádio Província 100.7 FM, nos três meses analisados, um total de 634 notícias, sendo $168(26,5 \%)$ sobre a Covid-19. Dessas 168, $85(50,5 \%)$ tratava-se de notícias próprias, 54 (32\%) foram produzidas por outros veículos de comunicação e 29 (17\%) notícias de assessorias. Do total de notícias que não foram criadas pela emissora, $83(49,5 \%), 28(34 \%)$ foram de meios nacionais e $55(66 \%)$ de estaduais e regionais, principalmente: Gaúcha ZH, 22 (26,5\%); Agência Brasil, 14 (17\%); Secom RS, 10 (12\%) e G1, 6 (7\%), isto é, dos 83 veículos de comunicação utilizados pela rádio para obter informações, 52 (62,5\%) foram dos quatro mencionados.

Assim como na Rádio Difusora, matérias que tratavam sobre o novo coronavírus na Região Celeiro foram postadas em maior número, 60 (35,5\%), seguidas da Covid-19 no Rio Grande do Sul e no Brasil, cada uma com 50 (30\%) e, por último, sobre a doença no mundo, com oito $(4,5 \%)$. Todas as matérias postadas no período analisado estavam abertas a comentários do público, e a Rádio Província foi a única emissora a recebe-los em 15 (9\%) notícias (14 com um comentário e uma com dois).

Não houve nenhuma notícia sem fonte postada e as principais utilizadas foram oficiais, em 107 (64\%) das 168, sendo as principais: governos, 68 (66,5\%), Ministério da Saúde, 26 (24\%) e hospitais, nove (8,5\%). Fontes não oficiais ocorreram em 59 (35\%) e fontes especializadas em duas $(1 \%)$. Nesse último caso, tratou-se de duas postagens diferentes de uma mesma matéria, produzida pelo Sistema Província de Comunicação sobre a opinião do Deputado Osmar Terra, que é médico, acerca da Covid-19, a única diferença entre as duas é que o título da que foi publicada primeiro possuía dois erros de português. A rádio foi a primeira da Região Celeiro a entrevistar o Deputado, que possui uma opinião diferente da OSM sobre a doença, a partir daí, outras emissoras fizeram o mesmo.

Também não houve nenhuma notícia com vídeos ou sem imagens para ilustrar o conteúdo. Apesar de a rádio utilizar, em sua maioria, fotos de outros meios, $68(40,5 \%)$, o 
número de imagens próprias dos comunicadores da emissora é próximo, 64 (38\%), em 36 $(21,5 \%)$; foram utilizadas fotos ilustrativas.

Apenas duas (1\%) matérias continham links, que levavam a sites de outros veículos de comunicação.

Por vezes, a emissora utiliza textos de outros meios e fotos próprias nas notícias, bem como imagens repetidas em matérias diferentes (ocorreu três vezes). Utilizam matérias produzidas para o jornal impresso do Sistema Província de Comunicação também no site.

Uma das matérias postadas no site é uma opinião de um dos locutores, com link para o site pessoal dele, entretanto, para saber que é um texto opinativo é necessário ler o conteúdo, pois não há quaisquer indicações fora do texto.

Algumas matérias não possuem créditos, levando a acreditar que são próprias, entretanto, os dados são estaduais, nacionais ou mundiais, informações que dificilmente seriam conseguidas por uma emissora de rádio pequena do interior, dessa forma, acreditase que sejam de assessorias de comunicação ou de outros meios. Os créditos de notícias de outros veículos (o nome do autor não é mencionado) são postados ao final do texto, por vezes com letra minúscula.

As matérias são, em sua maioria, curtas, de dois a cinco parágrafos, que vai ao encontro do que autores que discutem jornalismo na internet recomendam, como Miranda (2004), por exemplo, que cita a importância de os textos jornalísticos para a internet serem objetivos, concisos e curtos. Não há blocos grandes de texto, entretanto, às vezes, as informações são muito rasas, deixando dúvidas acerca do conteúdo postado.

Quadro 5. Palavras mais utilizadas nos títulos das notícias da Rádio Província 100.7 FM

\begin{tabular}{|l|l|}
\hline Coronavírus: 65 & Quarentena: 2 \\
\hline COVID19: 22 & Hospital/UPA/Lacen: 10 \\
\hline Pandemia: 5 & Morte: 15 \\
\hline Calamidade (pública): 1 & Auxílio (R 600,00$): 2$ \\
\hline Suspensão: 5 & Decreto: 6 \\
\hline Ministério da Saúde: 4 & Emergência/emergencial: 3 \\
\hline
\end{tabular}

Fonte: a autora (2020).

No que se refere às palavras mais impactantes, "Coronavírus" foi utilizada com maior frequência, em 65 dos títulos, enquanto "Covid-19" foi utilizada em 22. "Morte" foi 
mencionada 15 vezes, sendo que a primeira ocorreu em 17 de março, dia em que houve a primeira morte causada pela doença no Brasil.

Os termos "Hospital/UPA/Lacen" foram utilizados 10 vezes, "Suspensão", cinco, "Ministério da Saúde", quatro e "Emergência/emergencial”, três. "Decreto" foi citado em seis títulos de matérias, a primeira em 20 de março, dois dias após a prefeitura publicar o decreto sobre as medidas de prevenção da Covid-19; "Pandemia" cinco vezes, a primeira em 23 de março, 12 dias após a OMS declarar a doença como pandêmica; “Auxílio (R\$ $600,00)$ " e "Quarentena" foram utilizadas duas vezes no dia 27 de março, dia em que a ajuda do Governo foi aprovada na Câmara dos Deputados; por fim, "Calamidade (pública)", citada em apenas um título, no dia 19 de março.

Quadro 6. Site da Rádio Querência 89.7 FM

\begin{tabular}{|c|c|c|c|}
\hline \multicolumn{4}{|c|}{ Notícias } \\
\hline $\begin{array}{lrl}\text { Total } & \text { de } & \text { outras } \\
\text { notícias: } 543 & \end{array}$ & $\begin{array}{l}\text { Total de notícias sobre } \\
\text { coronavírus: } 145\end{array}$ & & \\
\hline Notícias próprias: 45 & $\begin{array}{l}\text { Notícias de } \\
\text { meios: } 71\end{array}$ & Notícias de Ascom: 29 & \\
\hline $\begin{array}{l}\text { Covid-19 no Mundo: } \\
14\end{array}$ & Covid-19 no Brasil: 44 & $\begin{array}{lc}\text { Covid-19 no } & \text { Rio } \\
\text { Grande do Sul: } 50 & \end{array}$ & $\begin{array}{l}\text { Covid-19 na Região: } \\
37\end{array}$ \\
\hline $\begin{array}{l}\text { Comentários ativados: } \\
0\end{array}$ & $\begin{array}{l}\text { Comentários } \\
\text { desativados: } 145\end{array}$ & Com comentários: 0 & Sem Comentários: 145 \\
\hline \multicolumn{4}{|c|}{ Fontes } \\
\hline Fontes oficiais: 90 & $\begin{array}{l}\text { Fontes especializadas: } \\
1\end{array}$ & Não oficiais: 53 & Sem fonte: 1 \\
\hline \multicolumn{4}{|c|}{ Fotos } \\
\hline Fotos próprias: 19 & Fotos ilustrativas: 72 & $\begin{array}{l}\text { Fotos de outros meios: } \\
54\end{array}$ & Sem fotos: 0 \\
\hline \multicolumn{4}{|c|}{ Vídeos } \\
\hline Vídeos próprios: 0 & De outros meios: 1 & Sem vídeos: 144 & \\
\hline \multicolumn{4}{|c|}{ Links } \\
\hline Para o próprio site: 1 & Para outros meios: 69 & Sem link: 75 & \\
\hline
\end{tabular}

Fonte: a autora (2020). 
No mês de janeiro foram nove dias sem postagens no site da emissora, em fevereiro foram oito dias e, em março, sete. Conteúdos sobre a Covid-19 foram postados em três dias diferentes em janeiro, quatro em fevereiro e 19 em março.

A Rádio Querência 89.7 FM publicou, durante o período de análise, 553 notícias em seu site, $145(26,7 \%)$ delas relacionadas ao novo coronavírus. Notícias de outros meios de comunicação foram as mais utilizadas, contabilizando 71 (49\%), seguidas de notícias próprias, 45 (31\%) e de assessorias de comunicação, 29 (20\%). Ao todo, 100 (69\%) matérias postadas no site não foram produzidas pela emissora, dessas, 30 (30\%) foram de meios nacionais e 70 (70\%) de estaduais e regionais, principalmente: Gaúcha ZH, 44 (44\%), Agência Brasil, 12 (12\%), G1, 11 (11\%) e Secom RS, 9 (9\%), o que quer dizer que dos 100 meios utilizados para obtenção de informações, 76 (76\%) foram dos quatro acima citados.

Ao contrário das outras duas emissoras, a Rádio Querência publicou um maior número de notícias relacionadas à Covid-19 no Rio Grande do Sul, 50 (34,5\%); Covid-19 no Brasil: 44 (30,5\%); Covid-19 na Região: 37 (25,5\%); Covid-19 no Mundo: 14 (9,5\%). Os comentários estavam desativados em todas as notícias publicadas no site da Rádio Querência no período analisado.

Apenas uma $(0,68 \%)$ das notícias publicadas não possuía fonte de informação especificada no texto, assim como somente uma $(0,68 \%)$ fonte especializada, um especialista em crimes. 0 número de fontes oficiais foi o maior, 90 (62\%), como nas outras emissoras, as fontes não oficiais totalizaram 53 (36,5\%) matérias. As principais fontes oficiais utilizadas foram: Governos: 66 (73,5\%); Ministério da Saúde: 9 (10\%); hospitais: 6 (6,5\%); OMS: 5 (5,5\%).

Todas as postagens possuíam fotos para ilustrar o texto, fotos ilustrativas foram as mais utilizadas, em 72 (49,5\%), seguidas por fotos de outros meios, 54 (37\%) e próprias, 19 (13\%). Apenas um vídeo $(0,68 \%)$ foi postado, criado por outro veículo de comunicação.

Link para o site da própria rádio foi postado em uma única matéria $(0,68 \%)$, links para outros meios em $69(47,5 \%)$ e 75 (51,5\%) notícias não possuíam.

Há notícias bastante longas, algumas ultrapassam 15 parágrafos, o que é muito longo para textos publicados na internet, visto que o cansaço ocular ou desconforto causado por leituras em telas luminosas é maior do que em páginas impressas. Há também notícias curtas, com dois parágrafos, essa diferença se deve ao fato de a Rádio fazer uso de conteúdo de diversos veículos de comunicação, que possuem características de texto diferentes. 
Quadro 7. Palavras mais utilizadas nos títulos das notícias da Rádio Querência 89.7 FM

\begin{tabular}{|l|l|}
\hline Coronavírus: 69 & Vacina: 2 \\
\hline COVID19: 7 & Hospital/UPA/Lacen: 4 \\
\hline Pandemia: 4 & Morte: 15 \\
\hline Calamidade (pública): 3 & Auxílio (R \$ 600,00): 3 \\
\hline Suspensão: 13 & Decreto: 5 \\
\hline Ministério da Saúde: 3 & Emergência/emergencial: 3 \\
\hline Quarentena: 0 & \\
\hline
\end{tabular}

Fonte: a autora (2020).

A Rádio Querência 89.7 FM foi a única que mencionou, em dois dos títulos de suas matérias a palavra "Vacina", no dia 18 de março. "Coronavírus", assim como no caso das demais emissoras, foi a palavra mais recorrente nas manchetes utilizada 69 vezes, enquanto "Covid-19" foi utilizada em sete. O termo "Morte", utilizado em 15 títulos, ocorreu primeiramente, no dia 28 de janeiro, sobre as vítimas fatais da doença no mundo; “Decreto" cinco, a primeira vez em 21 de março, dia da assinatura do decreto em Santo Augusto; "Pandemia” quatro, sendo a primeira em 24 de março; “Calamidade (pública)” três, 19 de março; “Auxílio (R\$ 600,00)” três, a primeira no dia 27 de março.

A palavra "Suspensão" ocorreu em 13 dos títulos; "Hospital/UPA/Lacen” em quatro, "Ministério da Saúde" em três, assim como "Emergência/emergencial”.

Apesar de a quarentena ter sido declarada, o termo não foi utilizado em nenhum título de notícias postadas no site da Rádio Querência no período analisado.

\section{Considerações Finais}

Com base na pesquisa aqui apresentada, foi possível observar um crescimento considerável na veiculação de notícias sobre a Covid-19 no mês de março pelas rádios Difusora 1350 AM, Província 100.7 FM e Querência 89.7 em seus sites, enquanto em janeiro e fevereiro as emissoras produziram uma média de pouco mais de $2,5 \%$ notícias sobre a pandemia (1,6\% Província, 3,1\% Querência e 3,2\% Difusora), em março esse número subiu para quase 50\% (34\% Difusora, 51\% Província e 61\% Querência). A produção de conteúdo das emissoras se manteve estável nos três meses, o que mudou foi a quantidade de notícias sobre o novo coronavírus.

Durante os três meses analisados, a emissora que mais veiculou matérias sobre a doença foi a rádio Querência, com $26,7 \%$, seguida da Província, com $26,5 \%$ e, por fim, a 
Difusora, com $11,5 \%$ de conteúdo postado relacionado à Covid-19. No que se refere à produção de material próprio ou utilização de notícias produzidas por outros meios de comunicação, a emissora que mais elaborou matérias foi a Província, com mais de 50\% de conteúdo próprio, $32 \%$ de notícias de outros meios e pouco mais de $17 \%$ de matérias elaboradas por assessorias de comunicação. Em seguida, a emissora Querência, com 31\% de notícias próprias, quase $49 \%$ de outros meios e $20 \%$ de assessorias. Por último, a rádio Difusora, que veiculou aproximadamente 15,5\% de conteúdo próprio, 46\% de notícias de outros meios e $38,50 \%$ de assessorias de comunicação.

No período das análises não havia nenhum caso confirmado de coronavírus na Região Celeiro, apenas casos suspeitos. 0 primeiro (caso suspeito) foi em Tenente Portela, no início do dia 18 de março, ao final do dia o número subiu para cinco. Os casos confirmados surgiram, na Região, a partir de abril. O fato de não ter havido nenhum caso de coronavírus na região durante o período analisado pode ter sido determinante para a falta tanto de imagens quanto de conteúdo próprio das emissoras.

Há, também, que se levar em consideração a falta de profissionais nas emissoras de rádio do interior principalmente no que se refere a Região Celeiro, sobretudo, profissionais com conhecimento em jornalismo. A publicação de notícias produzidas por outros veículos facilita e agiliza o fornecimento de informações àqueles que acessam os sites das emissoras. Essa prática se torna um problema a partir do momento em que os créditos da origem do conteúdo não são mencionados.

$\mathrm{Na}$ maior parte das notícias das três emissoras não há blocos grandes de texto, exceto quando são publicados decretos na íntegra. Há algumas notícias com informações rasas e incompletas, deixando dúvidas acerca do conteúdo postado, dando a entender que a notícia foi veiculada para não "ficar para trás" de outros meios.

O fato de nem todas as notícias possuírem espaço aberto para que o público possa comentar, como no caso da Rádio Querência, pode ser justificado pelas discussões, brigas e polêmicas que eles podem causar. Assim como a internet possibilitou maior acesso à informação, acabou também facilitando a disseminação de ódio, preconceitos e ameaças, visto que há internautas que usam o meio para esse fim, ainda crendo que é "uma terra sem lei". Nas emissoras de rádio, por exemplo, o comunicador é um "filtro" de comentários, que transmite ao público aqueles que julga importantes ou interessantes.

Percebe-se também uma busca pela segurança na utilização de fontes oficiais, a partir de dados divulgados por governos, hospitais e a própria OMS. Em tempos de notícias 
falsas circulando, sobretudo, na internet, cuidados com as informações divulgadas se fazem necessários.

\section{Referências}

BARDIN, L. Análise de conteúdo. Tradução de Luís Antero Reto e Augusto Pinheiro. São Paulo: Edições 70, 1977.

BRASIL. Presidência da República. Secretaria de Comunicação Social. Pesquisa brasileira de mídia 2016: relatório final. Brasília: Secom, 2016.

BROTE de enfermedad por coronavirus (COVID-19). Organização Mundial da Saúde, 2020a. Disponível em: <https://www.who.int/es/emergencies/diseases/novel-coronavirus-2019>. Acesso em: 20 mai. 2020.

CEBRIÁN HERREROS, M. La radio en Internet - de la ciberradio a las redes sociales y la radio móvil. Buenos Aires: La Crujía, 2008.

COM casos confirmados em 13 países, coronavírus é transmissível antes dos sintomas aparecerem. BBC News Brasil, 26 jan. 2020. Disponível em: <https://www.bbc.com/portuguese/geral-51258799>. Acesso em: 26 mar. 2020.

FERRARETTO, L. A. Rádio: o veículo, a história e a técnica. 2. ed. Porto Alegre: Sagra Luzzatto, 375 p., 2001.

KANTAR IBOPE MEDIA. Book de Rádio 2018. 2018. Disponível em: <https://www.kantaribopemedia.com/wp-content/uploads/2018/09/Book-de-

R\%C3\%A1dio-2018_Final.pdf>. Acesso em: 18 jul. 2019.

KISCHINHEVSKY, M. Radiojornalismo comunitário em mídias sociais e microblogs: circulação de conteúdos publicados no portal RadioTube. Estudos em Jornalismo e Mídia, Florianópolis: Programa de Pós-Graduação em Jornalismo UFSC, v. 9, n. 1, p. 136-148, jan./jun. 2012.

LOPEZ, D. C. Radiojornalismo e convergência tecnológica: uma proposta de classificação. XXXII Congresso Brasileiro de Ciências da Comunicação, Curitiba, 2009.

MIRANDA, L. Jornalismo on-line. Passo Fundo: UPF, 2004.

OMS declara pandemia de coronavírus. G1, 11 mar. 2020. Disponível em: <https://g1.globo.com/bemestar/coronavirus/noticia/2020/03/11/oms-declara-pandemiade-coronavirus.ghtml>. Acesso em: 20 mai. 2020. 
ORTRIWANO, G. S. Radiojornalismo no Brasil: fragmentos de história. REVISTA USP, São Paulo, n.56, p. 66-85, dez./fev. 2002-2003.

PRATA, N. Webradio: novos gêneros, novas formas de interação. Florianópolis: Insular, 2009.

PREGUNTAS y respuestas sobre la enfermedad por coronavirus (COVID-19). Organização Mundial da 2020b. Saúde, Disponível em: <https://www.who.int/es/emergencies/diseases/novel-coronavirus-2019/advice-forpublic/q-a-coronaviruses>. Acesso em: 20 mai. 2020.

RÁDIO DIFUSORA AM 1350. Site. Disponível em: <https://rd3.net.br/>. Acesso em: $01 \mathrm{abr}$. 2020.

RÁDIO PROVÍNCIA 100.7 FM. Site. Disponível em: <http://www.yucuma.com.br/>. Acesso em: 01 abr. 2020.

RÁDIO QUERÊNCIA 89.7 FM. Site. Disponível em: <https://www.querenciaonline.com/>. Acesso em: 01 abr. 2020. 


\section{Como citar este artigo}

TRENTIN, Lidia Paula. Pandemia: a veiculação de notícias sobre a Covid-19 nos sites de emissoras de rádio da região Celeiro, RS. Revista Dispositiva. [on-line] Disponível em: <http://periodicos.pucminas.br/index.php/dis positiva> Dossiê: Comunicação, política e saúde. Editoras Responsáveis: Fernanda Sanglard e Vanessa Veiga de Oliveira. Volume 9 , Número 16, Belo Horizonte, dezembro de 2020, p. 168-187. Acesso em “dia/mês/ano".

Texto recebido em: $21 / 07 / 2020$

Texto aprovado em: 16/12/2020 